\title{
Working Happiness in the Human Resource of a University Organization Based on Seligman's PERMA Model
}

\author{
PhD Augusto Renato Pérez Mayo \\ Faculty of Accounting, Administration and Informatics \\ Autonomous University of the State of Morelos (Cuernavaca, Morelos, Mexico) ORCID: \\ 0000-0003-1094-3283 (Corresponding author) \\ E-mail: renatomayo@hotmail.com
}

EGRH. Edgar Bahena Velazco

Student of the Specialty in Human Resource Management

Faculty of Accounting, Administration and Informatics

Autonomous University of the State of Morelos (Cuernavaca, Morelos, Mexico)

PhD Nohemí Roque Nieto

Faculty of Accounting, Administration and Informatics

Autonomous University of the State of Morelos (Cuernavaca, Morelos, Mexico) ORCID:

0000-0002-3546-0213

PhD. Pablo Guerrero Sánchez

Autonomous University of the State of Morelos (Cuernavaca, Morelos, Mexico)

ORCID: 0000-0003-2701-8393

Received: Aug. 24, 2019 Accepted: Sep. 18, 2019 Online published: Oct. 28, 2019

doi:10.5296/ijhrs.v9i4.15718 URL: https://doi.org/10.5296/ijhrs.v9i4.15718 


\section{Abstract}

The article reviews the levels of working happiness of Human Resources working in a university organization in Mexico; was done the theoretical route under the gaze of the Welfare Theory proposed by Seligman (2010) and followers like Steen, Park, Peterson Salanova, Martinez and Llorens (2005), Contreras and Esguerra (2006) and others, as an explanatory framework that highlights the importance of identifying levels of happiness in work and in life, in an organization university. The methodology is empirical, descriptive and quantitative. The instrument used for data collection was the PERMA model. This instrument allowed identifying the levels of work happiness and the levels of happiness with life based on the methodological categorical criteria proposed by it were measured the following dimensions: Positive Emotions, Commitment, Positive Relationships, Meaning and Achievements. In the results of labor happiness an average of $31.34 \%$ was found, which is interpreted as poor happiness with their work. In the results of happiness in life the average was $33.79 \%$, with which we could affirm that workers are deficient in happiness in their lives, which impacts on their emotional health and obviously on their work performance. An organization with poor organizational health.

Keywords: work happiness, human resource, university organization, model PERMA

\section{Introduction}

Happiness has always been in force as a subject of reasoning and dissertation on human issues, clarifying them involves delimiting their particularity, and this is difficult to understand, given the multiple likelihood of approach and the multiple attitudes are involved in their conceptualization which, of course, are protected by perceptions of each historical moment. Despite how transcendental happiness is in the lives of human beings and the numerous approaches that intellectuals and academics have made of it, there is a significant lack of research on how to achieve it at least in Mexico and its surroundings. For a long time, psychological and administrative research focused solely on the exposure of the negative (Seligman, 2002). The past decade was a great example of what happened. It was discovered that, for every hundred scientific articles on sadness, only one was reported on happiness (Seligman, 2002). In the organizational slang has happened the same, for several decades the worker has been defined from a negative representation (Salanova, Martínez and Llorens, 2005); and this, in turn, has created the I work as a negative thing.

But this event now seems to be changing; thanks, among other things, to the entry of positive psychology and considerable growth in research from a healthy approach (Seligman, Steen, Park, and Peterson, 2005). This shows the consolidation of a new side that focuses not on the treatment of the disease, but on the promotion of positive emotions (Contreras and Esguerra, 2006).

Research focused on studying the topic of happiness at work has shown that the adoption of positive practices has a positive impact on performance, productivity and, above all, the possibility of personal expectations, workers' families and social workers are being realized through strategies aimed at achieving these results (Lyubomirsky, 2008).

From the best of this, it is inevitable to study in what arrangement, the university 
organization(Faculty of Accounting, Administration and Computer Science of the UAEM),perform skills to boost and develop happiness, and what are the scopes achieved with these experiences; with the intention of learning more about the situation and driving new work events, where the uneven categories of organizations incorporate emotional and socially beneficial lifestyles, which rest in privilege, not only the productivity of the but also of consistent progress with new perspectives that have the challenge of improvement in their integral capacity. Hence the recent description aspires to be, but a consultation, at least a contribution to the current work environment of our institution.

\section{Literature Review}

Happiness has always been in force as a subject of reasoning and dissertation on human issues, clarifying them involves delimiting their particularity, and this is difficult to understand, given the multiple likelihood of approach and the multiple attitudes are involved in their conceptualization which, of course, are protected by perceptions of each historical moment.

Research focused on studying the topic of happiness at work has shown that the adoption of positive practices has a positive impact on performance, productivity and, above all, the possibility of personal expectations, workers' families and social workers are being realized through strategies aimed at achieving these results (Lyubomirsky, 2008).

From the best of this, it is inevitable to study in what arrangement, the people who work in the Faculty of Accounting, Administration and Computer Science (FCAeI),perform skills that promote and promote bring happiness, and what are the scopes achieved with such experiences; with the intention of learning more about this situation and driving new working environments, where the uneven categories of organizations incorporate emotional and socially beneficial life styles to, which are privileged, not only of the productivity of the organization, but also of consistent progress with the new perspectives that have the challenge of improving their end-to-end capacity. Hence the recent description aspires to be, but a consultation, at least a contribution to the current work environment of the university organization.

The Theory of Welfare (or PERMA Model) is basically an unobligated designation theory and is a representation of what individuals freely prefer to increase their happiness. Seligman himself replaces the object of research with this theory, from researching happiness (1999) to studying welfare (2010) which is more extensive and valuable.

Each component of the PERMA Model must play three elements to be a mechanism within the theory:

1. It must support the welfare of the individual.

2. Must be selected by conviction.

3. It must be determined and balanced autonomously to the rest of the model variables.

Today organizations appreciate more to their primordial capital, which are human beings, to 
establish the resources that organizations must give to their workers to achieve this happiness is difficult, since each organization is different, as is the individual inside organization. Each collaborator's stimulations and goals can be very different from each other, for example, there are human beings who are happy when they discover the "work of their dreams" (i.e. when they are finally employed in a place that agrees to deploy their preparation, where they believe that their contributions are perfect for the occupations to be made and where they are passionate about what they do) and others in which they are not interested in the responsibility or position that they get always feel dissatisfied and unhappy.

There are many organizations that have good management, but bad leaders, as administrators manage routine activities very well, but a leader is the one who wonders whether those instructions would be fully implemented since this kind of work hangs creativity and change. (Bennis, 2000).

Large companies that already acquire as a preference to their employees, put special energy from the moment of hiring and attracting the human resource, by certifying that the skills and desires of the applicants are in the same direction with the demands and objectives of organizations. In other cases the large investments that are implemented are for the distractions of workers to achieve greater education, because while it is true some organizations stimulate them extrinsically as with the salary, it is also evidenced that this type of stimulation does not always intervene positively in human resources instantly to be productive, because the instant they discover a job with a higher salary, they will leave their workplaces and always seek find something else, unlike those who receive an intrinsic and / or transcendental stimulation that allows them professional and particular development, they are more dedicated to their work and more loyal to the organization.

Considering Seligman's PERMA model, on organizational happiness, Ignacio Fernández wrote a book called "Model of Happiness in Work", which offers a guide to be able to change the model of an organization. For Fernandez, organizations begin with intuition when they make knowledge of happiness in order to make their workers satisfied, happy. This knowledge is then transformed into safety when it is discovered that they develop their capabilities and strengths and at the same time have a greater responsibility. That is, it goes from an instrumental orientation to an ethical orientation (Fernández, 2015).

An organization with these particularities is the ideal of most of them, but it obeys the reality of very few: there is a dominant number that do not fit the profile. The main speculation of this gravitates to the fact that the exercise of the latter is based on different types of fear: private (loss of employment), productive (competitiveness), economic (interest rates), scientists (the competitor's destructive technology), conflicts (possible strikes), and other things.

\section{Description of the Method}

This research includes a descriptive study with a quantitative approach. In this sense, descriptive studies seek to specify the properties, characteristics and profiles of people, groups, communities, processes, objects or any other phenomenon that undergoes an analysis, 
their purpose is to measure in a way the variables that will allow evidence of the study of the particular phenomenon and establish relations (Hernández, 2014). What you want with this research, is just to describe the level of work happiness and the level of happiness in life, of the people who work of a university organization Mexico.

The design of this research can be defined as non-experimental. Non-experimental research is to observe phenomena as they occur in their natural context, and then analyse them (Hernández, 2014). The data collection for this study was done cross-cuttingly as the data collection was in a limited time. The population sample for this study is 39 subjects, at $100 \%$ of the administrative employees of the FCAeI. PERMA's questionnaire was applied that measures general conceptual elements (subjective welfare, work happiness, institutional behaviours, strategy) noted in the model PERMA (positive emotions, commitment, relationships, meaning and achievement).

\section{Results}

\subsection{Findings from Documentary Review}

One thing we should highlight first is that, in Morelos, according to the documentary review carried out there are no works on the subject developed. On happiness at work, in Morelos, there are no research papers on it. Research was found with proposals for strong strategies for the development of happiness in individuals, the most significant being those of Lyubormirsky and Seligman in Latin America (Peru), in Mexico, there are few published researches. Seligman, it's considered the father of Positive Psychology, he faced the conception of subjective welfare and, from this one, instituted the five constituent categories of the PERMA model. Insisting on that, the compendiums of the PERMA model, together with the skills determined by Lyubomirsky and Fordyce, with conceptions of positive psychology such as work happiness, subjective well-being and institutional behaviours, were those that it's used to support the creation of the questionnaire implemented to examine the perception of happiness at work in the environment of the FCAeI. Denning the high predominance of positive psychology.

Seligman is, of the writers examined, the most appreciable in the subject, and for obvious reasons, the most accredited in the field of positive psychology; their proposals enjoy great recognition and approval, since they were published (2003). Seligman stresses that, positive thinking approves of individuals ordering their speeches and labours from gratitude, generosity, humour and creativity, and that when these situations are experienced in institutions, the effects tend to be superior productivity, profitability and organizational climate processes. Climate and performance assessment will possess this outcome when individuals who are part of the institution consent to these exercises being established as part of their culture. This is how positive impressions can not only help everyone in their internal domain but help in the work and social environments. We have organizations with good organizational health and others with poor health. 
4.2 Findings From the Application of the Instrument in the University Organization

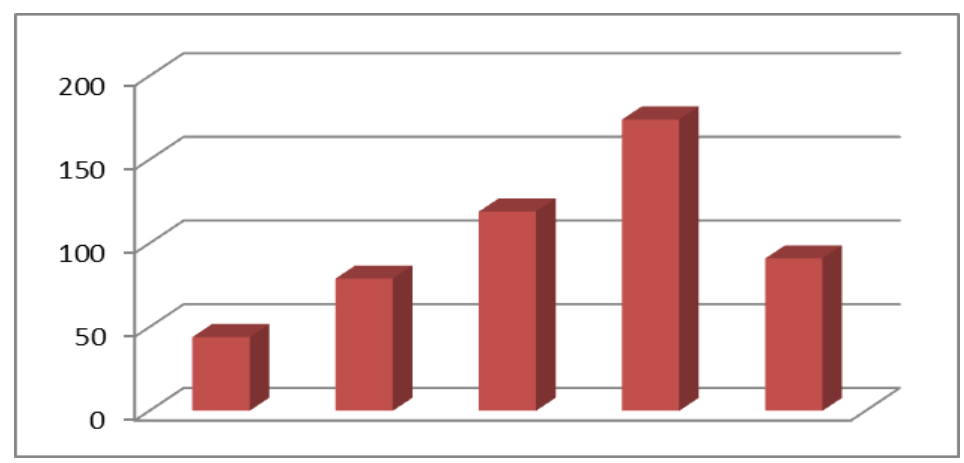

Graph 1. Results of the instrument's implementation

Source: Own elaboration, based on data obtained from the implementation of the instrument

\section{Explanation}

Regarding work happiness, an average of $31.34 \%$ was found, which is interpreted as happiness in poor work. According to Seligman's proposal, Positive Emotions, it is the component that most relates to the conclusion of happiness that is socially treated in current times. It is described to the greatest sum of positive emotions that are manifested throughout the day, a human being who exposes being happy lives emotions such as satisfaction, willingness to love, trust, illusion and other pleasant feelings. It is significant to bear in mind that there is a correspondence between positive emotions and negative emotions, when swinging both and when applying to one or the other, the appreciation of human happiness will point out which prevails, the greater the positive, the greater the happiness and better Prosperity and quality of life. The main objective of this measure was to find representations to conquer positive emotions and indulge in the practice of day-to-day life, help them not to abandon later with tiny daily actions, surround themselves with positive and developed-minded individuals. In this sense, the result shows that it is an organization with poor organizational health.

The other factors that were measured as Commitment (Engagement), Relationship (Relationship), Purpose and Meaning (Meaning), Accomplishment (Accomplishment), are important, however, they cover other factors that do not necessarily relate to happiness at work.

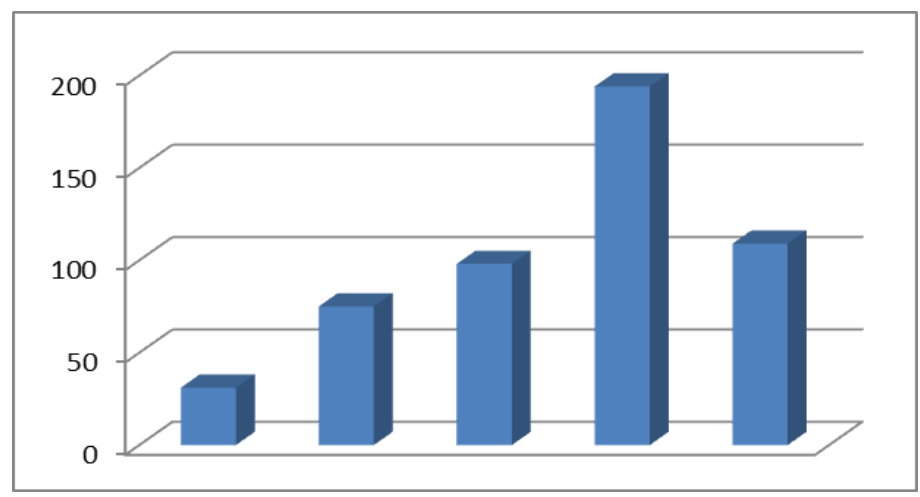

Graph 2. Happiness with life 
Source: Own elaboration, based on data obtained from the implementation of the instrument

\section{Explanation}

Happiness in life the average in the Faculty of Accounting, Administration and Informatics reached an average of $33.79 \%$, with which we could say that the result is interpreted as happiness with life is poor. They have good relationships, they find a purpose for what they do, and they have valuable achievements, however they do it for what it should be.

Performing an analysis of the results of the inventory of authentic happiness with work and life, we can realize that subsections A and B that speaks of bad mood, reflect that workers lose the sense of control of their mood and They experience malaise in general. That is why negative emotions are currently one of the main risk factors for contracting physical and mental illness.

\section{Conclusions and Recommendations}

Happiness has always been in force as a subject of reasoning and dissertation on human issues, specifying them involves delimiting their particularity, and it is difficult to understand, given the likelihood of approach and attitudes involved in their conceptualization that, of course, are covered by the perceptions of each historical moment.

Despite how transcendental happiness is in the lives of human beings and the numerous approaches that intellectuals and academics have made of it, there is a significant lack of research on how to achieve it. For a long time, psychological and administrative research focused almost solely on the exposure of the negative (Seligman, 2002). The past decade was a great example of what happened.

Happiness as a "practice", admits to experiencing emotions of satisfaction and joy with oneself, with others and in general with life, happiness is used as a traffic light of the social and emotional task of individuals (Bar-On, 2013). It is not interest of good luck or chance, it is not something that is obtained with wealth or power, it does not obey from the outside but of the character as this is shown and revealed (Csikszentmihalyi, 2007). Happiness is magnificent, unique, resides within us and has nothing to do with collecting goods.

Seligman maintains that human behaviour is not established by a review of awards and punishments, the causes of the individual's procedure are found in mental events, such as maturing or will. Before executing an operation, we first reason consecutively through internal psychic impulses that induce the human being to activity, to the optional exercises that constitute part of the lineage of the human being. Unlike the psychological ones that involve the human being a passive being, manifested by provocations, positive psychology meditates that the individual can make his own decisions, make choices and establish preferences, strengths, and virtues learn skills to free yourself from feelings of courage. You can practice controlling your proper actions and establish their use, the tasks carry a volatile background, a word handled by the old mentalist psychology and which positive psychology highlights.

Based on this review, we have presented contributions from Positive Psychology about 
happiness and its influences in the organizational and productivity field.

With potential contribution, the issue of happiness has been addressed in the Faculty of Accounting, Administration and Computer Science and we can conclude this research by demonstrating that positive psychology, should focus on the paths to happiness as far as happiness it can be presented, as the bridge necessary to set aside the philosophical search for the sovereign principle of happiness which, after all, are not incompatible with each other and can be pursued simultaneously to obtain happiness.

\section{Recommendations}

The PERMA model is an accurate proof of the likelihood of specificity of categories and strategies, suitable for carrying out, monitoring and examining in an integrated way dynamics and activities suitable for subjective well-being and work happiness, and, laying lines explanatory and demonstrative of the connection between them and the productivity of the institutions, because of their systematic, perceptible and measurable nature.

This practical theoretical model endorses strategic advantages for the institutions that make it, because it manages to establish that: adjusted in motivation and skills, the potential of individuals is perfected, management is progressed, management is obtained healthier institutions, and productivity rises.

Positive psychology and its derivative PERMA model have gained wide dissemination and acceptance in the USA and Europe; in Latin America important approaches to their understanding and implementation in institutional academic contexts are already visible. Mexico is one of the countries that has stormed the issue significantly.

However, to an important extent, the contents of work happiness, subjective prosperity and other partners, remain confined to second horizons of interest; one of the viable reasons is the issue of building honest indicators, they continue to be a stumbling block to highlight in the institutions of our medium. However, it must be examined that it is becoming notorious, thanks to the welfare techniques and the strategic direction of the institutions, the intention to change this reality.

Furthermore, it should be noted that the results of the implementation of the instrument in this research, present inaccuracies in its design, implementation and evaluation, expound coherence with what is determined by theory and PERMA model. This discovery is desirable with the established in the current research, that the promotion of happiness in employees impacts on the performance and productivity achieved when the institution designs wellness plans.

The results of the methodological mechanism under consideration contribute to the verification of the question and the achievement of the objectives of the research. It is no longer feasible or longed to maintain the instrumental vision of work and collaborator. While subjects should be responsible for happiness, institutions should promote it as part of their strategic goals. 


\section{Macrothink}

\section{Acknowledgment}

We thank the Program for the Strengthening of Educational Quality (P / PFCE-2019/) for the support granted for the publication of this article research and that has to do with the improvement of the academic productivity of the Academic Bodies of the FCAeI.

\section{References}

Bennis, W. (2000). Dirigir personas es como adiestrar gatos. Madrid.

Contreras, F. Y., \& Esguerra, G. (2006, julio-diciembre). Psicología positiva: una nueva perspectiva en psicología. En Diversitas. Perspectivas en Psicología, 2, 311-319. https://doi.org/10.15332/s1794-9998.2006.0002.10

Csikszentmihalyi, M. (2007). Fluir. (12². Ed.). Barcelona: Kairós.

Fernández, I. (2015). Felicidad Organizacional y Gestión de Personas. Recuperado el 10 de Marzo de 2017, de http://ignaciofernandez.blogspot.pe/2015/05/felicidad-organizacional-y-gestion de.html

Hernández, S. R. (2014) Metodología de la Investigación. 6a, edición, México, DF.

Lyubomirsky, S. (2008). The How of Happiness. New York.

Salanova, M., Martínez, I. M., \& Llorens, S. (2005). Psicología Organizacional. Positiva. En F. Palací (Ed.), Psicología de la Organización. Madrid: Pearson Prentice Hall, 349-376.

Seligman M.E. P. (2002). La auténtica felicidad. Ediciones.

Seligman, M. E., Steen, T. A., Park, N., \& Peterson, C. (2005). Positive psychology progress: empirical validation of interventions, En American psychologist, 60(5), 410. https://doi.org/10.1037/0003-066X.60.5.410

Seligman, M. E. P. (2003). La auténtica felicidad. (2ª Ed.). Barcelona: Ediciones B.

\section{Copyright Disclaimer}

Copyright for this article is retained by the author(s), with first publication rights granted to the journal.

This is an open-access article distributed under the terms and conditions of the Creative Commons Attribution license (http://creativecommons.org/licenses/by/4.0/). 